\title{
ESTADO, CONSTITUIÇÃO E DIREITOS SOCIAIS
}

\author{
STATE, CONSTITUTION AND SOCIAL RIGHTS
}

Carlos Miguel Herrera ${ }^{1}$

\begin{abstract}
Resumo:
Este artigo pretende analisar algumas questões referentes à história da incorporação dos direitos sociais nas constituições democráticas, especialmente a questão central do Estado Social.

Palavras-Chave: Estado Social. Direitos Sociais. Direitos dos Trabalhadores. História Constitucional.
\end{abstract}

\begin{abstract}
:
The purpose of this article is to examine some issues concerning the history of the incorporation of social rights in democratic constitutions, specially the central issue of the Social State.
\end{abstract}

Keywords: Social State. Social Rights. Worker's Rights. Constitutional History.

Introdução

Convém, talvez, começar precisando que a expressão "direitos sociais" será utilizada aqui de maneira convencional: seu uso não presume sua pertinência teórica. Contudo, não é casual que partamos da denominação corrente - que resume por sua vez a de "direitos econômicos, sociais e culturais" -, já que os problemas de expressão são centrais neste campo do Direito, talvez mais do que em qualquer outro, sobretudo quando se pensa que a doutrina jurídica surge freqüentemente em atraso em relação à positivação constitucional. Com efeito, quando se encontram enunciados normativos sobre os "direitos sociais" na maior parte das constituições ocidentais redigidas nos últimos trinta anos, a doutrina dominante na maioria dos países europeus se mostra sempre disposta a sustentar que eles não seriam autênticos direitos, exigíveis no sentido técnico-jurídico do termo,

\footnotetext{
1 Professor Catedrático de Direito Público, Université de Cergy-Pontoise, França. Membro do Institut Universitaire de France e Diretor do Centre de Philosophie Juridique et Politique da Université de CergyPontoise. O Autor é convidado especial do presidente da Comissão de Publicação, Professor Titular Enrique Ricardo Lewandowski, e do Professor Associado do Departamento de Direito Econômico-Financeiro Gilberto Bercovici. A versão original deste trabalho foi apresentada no Colóquio Internacional Droits de l'Homme, Menschenrechte, Civil Rights, organizado pelo Centre Marc Bloch Deutsch-Französisches Forshungszentrum für Sozialwissenschaft, de Berlim, na Humboldt Universität, em 15 de junho de 2002, e publicada na Revue Universelle des Droits de l'Homme, v. 16, n. 1-4, p. 32-39, out. 2004. A versão em espanhol foi publicada na Revista Derecho del Estado, n. 15, Bogotá, p. 75-92, dez. 2003. A presente tradução da versão espanhola para o português foi feita por Luciana Caplan.
} 
mas pelo contrário "objetivos", "fins", "princípios", não-justiciáveis perante (e pelos) tribunais. Não seriam exigíveis porque o Estado, e menos ainda o Estado democrático, não pode ser obrigado por uma autoridade judicial a fazer algo, enquanto que, pelo contrário, pode ser compelido a abster-se no campo dos direitos e liberdades individuais.

A doutrina jurídica alemã, que foi a primeira a analisar sistematicamente a questão, considera, majoritariamente, que não se trata de direitos garantidos constitucionalmente, entendidos como direitos subjetivos, para empregar uma expressão tradicional, ou seja, diretamente aplicáveis e, portanto, invocáveis de maneira autônoma perante os tribunais. ${ }^{2}$ Esta conclusão é o corolário de debates mais amplos que tiveram lugar ainda no início dos anos 1950, em que se negava o caráter jurídico-constitucional à noção de "Estado social", retirada da Grundgesetz. ${ }^{3}$ A influência desta discussão herdeira, por sua vez, de outras polêmicas surgidas ao final da República de Weimar foi notável e persistente, não-só no plano da doutrina mas também no do direito positivo europeu. Assim, a Constituição espanhola de 1978 preferiu apresentar os artigos referentes à matéria social como "princípios dirigentes (principios rectores) da política social e econômica". Não nos encontraríamos, uma vez mais, diante de "direitos subjetivos", mas de padrões que devem orientar a ação do Estado, sobretudo do Legislador, e, no melhor dos casos, a interpretação constitucional de normas jurídicas.

Esta conclusão resulta de uma suposta diferença de "natureza jurídica" entre direitos individuais e "direitos sociais", às vezes tematizada por distinções como "direitos de liberdade" e "direitos crédito" (droits-créances) ou de "direito (ou liberdade) de" e "direito a", implicando os primeiros em uma abstenção do Estado, enquanto os segundos conduziriam a uma prestação material. Uma vez definidos como obrigações (prestações) ligadas à atribuição de bens, considera-se que os direitos sociais não são direitos fundamentais no mesmo sentido que os direitos do homem, já que estes, por definição, precedem à sociedade, enquanto que os outros são obrigações que não existem até que se tenha constituído a sociedade, um Estado que permitirá que sejam colocados em funcionamento os serviços públicos destinados a satisfazer as necessidades sociais por meio de prestações materiais.

Pretendemos discutir aqui esta representação que estabelece uma diferença de essência entre os direitos do homem e os direitos sociais, em que as dificuldades técnico-

\footnotetext{
2 Para uma síntese, ver AUTEXIER, Christian. Introduction au droit public allemand. Paris: PUF, 1997. p. 109.

3 Ver a posição de E. Forsthoff na reunião da Associação Alemã de Professores de Direito Público em 1953, agora em FORSTHOFF, E. Rechtsstaat im Wandel. München: Beck, 1976.
} 
jurídicas para a realização efetiva destes últimos não seriam mais que uma conseqüência dessa natureza contraposta. E porque não há uma "natureza" própria aos direitos sociais, é na história de sua constitucionalização que se poderão determinar seus diferentes níveis de significação. Não é casual que a doutrina jurídica francesa apresente suas diferenças, ainda que de maneira secundária, em termos de "gerações" de direitos. Mas se esta distinção entre direitos do homem e direitos sociais é, antes de tudo, histórica, isto significa também que é contingente. Em todo caso, o primeiro obstáculo que se apresenta à juridicidade dos direitos sociais, sempre em relação com os direitos individuais, ou seja, que aqueles exigem uma ação positiva do Estado, não parece um fundamento suficiente para construir uma categoria teórica diferente. Dito de outro modo, a definição dos direitos sociais como direitos à prestações é também produto de uma história (política). Por certo, uma apresentação diacrônica dos diferentes direitos do homem é sempre concebível, porque sua significação variou com a evolução de certas relações sociais, mas isto não deve se confundir com uma natureza particular, "social" ou "econômica", de certos direitos fundamentais. O que nos conduz, em outras palavras, a sustentar a universalidade do social, a negar sua particularidade.

Um olhar sobre a aparição dos direitos sociais permitirá relativizar alguns obstáculos que a doutrina jurídica tradicional sustenta como inibitórios para sua completa caracterização jurídica. Mas não pretendemos traçar aqui uma história integral dos direitos sociais, e, menos ainda, legitimar uma tese teórica por seu fundamento histórico. $\mathrm{O}$ que aparece nas distintas formas de constitucionalização dos direitos sociais são duas lógicas em conflito, uma das quais foi deslocada, ou ao menos ocultada, pela evolução contemporânea do Estado social. Com efeito, existe uma tensão própria aos direitos sociais entre dois pólos, de emancipação social, por um lado, e de integração social, pelo outro, e que condiciona, por sua vez, o par conceitual utilizado para determinar seu caráter, universalidade e particularidade.

A dificuldade deste enfoque reside na sobreposição de momentos e de tradições. Mas ainda com o risco de um certo esquematismo, a identificação de ambos os pólos pode se revelar determinante, levando-se em conta que a modalidade conceitual que nega o caráter jurídico dos direitos sociais, para limitá-los a meras "políticas", combina em sua definição uma função política de integração social com sua caracterização como direitos particulares - seja quanto ao objeto (prestações materiais), seja no tocante à categoria de sujeitos beneficiários (os indigentes). Nesse sentido, nossa análise se deterá mais nas descontinuidades do processo de constitucionalização do social, em suas rupturas. 
O que equivale, no fundo, a sublinhar o caráter político dos direitos do homem, de todos os direitos do homem.

\section{Direitos Sociais e Revolução Social}

A codificação de direitos do homem em uma declaração, tal como aparece em fins do século XVIII, expressa a tentativa de constitucionalizar um movimento insurrecional. Mas, no caso dos direitos humanos de conteúdo social, esta intenção parece ser expressada de forma mais direta. É por isso que a referência a sua "transcendência" parece reduzir-se aqui ao mínimo, para transformar-se em um projeto político. Diferentemente também dos direitos do homem de conteúdo individual, os direitos sociais aparecem sempre como fruto de uma revolução inconclusa, não apenas no sentido de movimentos que não conseguem realizar seu programa original - o que poderia ser só uma constatação banal desde o ponto de vista histórico - , mas na idéia de que esta deve ser terminada por e em um novo ordenamento jurídico (positivo). Isto explica, uma vez mais, porque os direitos sociais se apresentam menos como direitos naturais, imprescritíveis e transcendentes que sob a forma de políticas (estatais). Um exemplo claro desta modalidade nos dão os termos do célebre decreto, de 25 de fevereiro de 1848, que impõe ao governo da II República francesa "garantir a existência do trabalhador através do trabalho, o Governo se compromete a garantir um trabalho a todos os cidadãos". ${ }^{4}$ Assim, desde o início, a idéia de direitos sociais, e mais particularmente, esta referência direta ao social, expressa esse ponto de passagem consciente da insurreição à instituição através de sua positivação (constitucionalização). Talvez quem tenha expressado mais claramente, em termos políticos, esta idéia foi um dos líderes mais influentes da Revolução, de 1848, Louis Blanc: "a reforma política não era mais que um meio para conseguir o objetivo, ou seja, a reforma social'. À medida em que esta conexão entre direitos sociais e mudança social se debilita, especialmente depois de 1945, com a generalização (relativa) de um modelo de Estado social, por um lado, e a aceitação definitiva (também relativa) dos direitos sociais no Direito Constitucional, por outro, sua significação teórica e jurídica se transformará.

$\mathrm{Na}$ verdade, a afirmação do caráter social dos direitos do homem encontrase de maneira explícita nos trabalhos do Comitê de Mendicância da Constituinte, que considera, em seu plano de trabalho de 1790, que "todo homem tem direito à sua

\footnotetext{
4 Esta pode ser uma das limitações das análises de Hannah Arendt sobre a questão social em On Revolution (1963), que opera como se, entre 1789 e Marx, não houvesse ocorrido a Revolução francesa, de fevereiro de 1848, descartada por ela muito rapidamente. Pelo contrário, é mérito de Anton Menger, e antes dele, de Lorenz von Stein, terem assinalado a sua importância.
} 
subsistência". Nesse sentido, o Comitê declara que ali onde se encontrem homens sem meios de subsistência, existe uma violação aos direitos do homem. ${ }^{5}$ Num discurso de junho de 1792, Bernard precisa que o direito à subsistência apresenta dois aspectos: o trabalho, se o homem é apto, ou os auxílios gratuitos, se não tem a possibilidade de fazê10. ${ }^{6}$ Quando a Constituição, de 1793 proclama, no art. 21 de sua célebre Declaração, um "direito aos auxílios públicos" para aqueles que não estão em condições de trabalhar, não faz mais que seguir uma das linhas de evolução presentes desde o início na Revolução de 1789, aquela justamente que associa este direito a uma categoria social, a indigência. Isto nos mostra também que a lógica de integração social dos direitos sociais está presente desde a origem, e é a primeira a ser constitucionalizada. ${ }^{7}$

Mas, junto a esta primeira tentativa de constitucionalização, subsiste outra lógica, que se encontra sobretudo em Robespierre, ao menos desde seu célebre Discurso da Subsistência. Ele defende ali o "direito à existência" como o "primeiro" direito imprescritível do homem, assumindo deste modo a universalidade do social. Mais ainda, radicaliza esta perspectiva, afirmando que tal direito implica na limitação do direito de propriedade, já que a subsistência obriga a "assegurar a todos os membros da sociedade o usufruto da porção de frutos da terra que é necessária para sua subsistência". ${ }^{8} \mathrm{~A}$ propriedade é "uma instituição social", tal como Robespierre afirma na apresentação de seu projeto de Declaração, em abril de 1793. Os principais direitos do homem reduzem-se ali a dois: "procurar a conservação da existência e a liberdade" (art. $2^{\circ}$ ). Nesse sentido, o caráter universal do direito à existência encontra-se nos dois meios que Robespierre explicita no item X da Declaração jacobina: “a sociedade está obrigada a prover a subsistência de todos seus membros, seja procurando-lhes trabalho ou assegurando os meios de existência a quem não esteja em condições de trabalhar".

Mas a questão constitucional instala-se com mais força em meados do século XIX, quando a questão social e os direitos sociais em sentido estrito convergem, se

\footnotetext{
5 Cit.em CASTEL, Robert. Les métamorphoses de la question sociale. Paris: Gallimard, 1999. p. 296. Vide também BORGETTO, Michel. La notion de fraternité en droit public français. Paris: PUF, 1993.

6 Cit. por BORGETTO, Michel. op. cit., p. 165.

7 As investigações históricas demonstraram como o primeiro desenvolvimento do Estado Social está ligado à responsabilidade frente aos pobres, para transformar-se logo na questão social. Para uma síntese, vide RITTER, Gerhard A. Der Sozialstaat. Entstehung und Entwicklung im internatinalen Vergleich. München: R. Olden-bourg, 1989. p. 19. Na França, os trabalhos de síntese defendem, por sua vez, esta tese, vide EWALD, François. L'État providence. Paris: Bernard Grasset, 1986; ROSANVALLON, Pierre. L'État en France de 1789 à nos jours (1990). Paris: Seuil, 2002; CASTEL, Robert. op. cit.

8 ROBESPIERRE, Maximilien. Textes Choisis: Discurso de 2 de dezembro de 1972. Paris: Éditions Sociales, 1957. tomo II.
} 
confundem, inclusive, com a aparição de um “quarto" estado como sujeito de direito. É assim que, em 1848, o problema dos direitos sociais concentra-se na discussão sobre um "direito ao trabalho", fórmula de origem fourierista que conhece uma grande popularidade neste momento. O caráter integral do "direito ao trabalho" aparece já no projeto constitucional de junho de 1848, em que são reconhecidas como garantias essenciais a esse direito, entre outras, a liberdade, a liberdade de associação, a igualdade, o ensino gratuito.

Como se pode prever, é nos escritos dos socialistas, de 1848, em que aparece teorizado de maneira mais direta o caráter universal dos direitos sociais. Para Blanc, o direito ao trabalho tem seu fundamento no direito a viver produtivamente, e por meio dele, ao direito de conservar a vida. O direito ao trabalho está ligado ao direito à propriedade por uma dupla via: toda propriedade que não provém do trabalho não está justificada, todo trabalho que não conduz à propriedade é opressivo. Para trabalhar, é necessário contar com os instrumentos de trabalho, do contrário, aqueles que não os têm estão submetidos a quem os possui. Se a desigualdade é um fato geral, permanente, Blanc afirma, pelo contrário, a variabilidade da idéia de propriedade, como assim também das de liberdade e livre concorrência. ${ }^{9}$ A afirmação do direito ao trabalho como negação do direito à propriedade aparece também em Proudhon, um nome significativo nesta história, não tanto por ter sido o conhecido motivo do rechaço a todo reconhecimento constitucional do direito ao trabalho, por haver pronunciado uma frase demasiado sincera na Assembléia Nacional, mas por não-associar em sua concepção este direito a um Estado produtor, como fazia Blanc. Com efeito, para o teórico do mutualismo, o direito ao trabalho não se reduz à promoção de obras públicas e ao aumento do gasto público; pelo contrário, está inscrito na idéia de uma constituição social, definida como "o equilíbrio de interesses fundado no livre contrato e na organização das Forças econômicas", e que opõe à constituição política, autoritária. ${ }^{10} \mathrm{Na}$ última tentativa parlamentar de incluir no texto constitucional o direito ao trabalho, Félix Pyat afirma sua continuidade com a tradição dos direitos do homem: "ao entrar em sociedade num mundo ocupado, compartilhado, parcelado, o homem troca seus direitos individuais por seus direitos sociais Quais são seus direitos

9 BLANC, Louis. Le Socialisme: le droit au travail (1848). In: Questions d'Aujourd'hui et de Demain. Paris: E. Dentu, 1882. T. IV. p. 320-323 e 361.

${ }^{10}$ PROUDHON, Pierre Joseph. Oeuvres Complètes: Le Droit au Travail et le Droit de Propriété. Nouvelle Edition. Paris: Librairie Marcel Rivière, 1926. Tomo X, p. 421; Les Confessions d'un Révolutionnaire (1849), Id. Ibid., Tomo II, p. 217. É «o destino da Constituição política o de provocar e produzir incessantemente a Constituição social». Proudhon verá na Constituição, de 1848, algo parcial, de fundo socialista, «uma expressão incompleta e disfarçada da Constituição social», mas incompatível com as atribuições políticas, o que a condena à impotência (p. 222). O que equivaleria dizer que a reforma política não pode gerar a reforma social. 
sociais? O trabalho e a propriedade". ${ }^{11}$ A prioridade, todavia, pertence ao trabalho, que é "a fonte e a garantia" da propriedade, porque o trabalho é o único meio de aquisição com que contam os pobres.

Um testemunho interessado destes debates constituintes sustenta que a fórmula "direito ao trabalho" não se torna central para os trabalhadores senão após a repressão sangrenta das revoltas de junho, "quando a Assembléia Nacional busca curar as cicatrizes deixadas pela (supressão dos) ateliers nacionais"; antes, os trabalhadores exigem "a organização do trabalho", o que equivaleria menos a um direito que a um novo sistema social. ${ }^{12} \mathrm{Na}$ realidade, ambas as questões encontram-se intimamente ligadas, como resulta da afirmação de François Vidal, secretário geral da Comissão de Luxemburgo, que sustenta que "o direito ao trabalho (...) implica necessariamente na organização do trabalho, e a organização do trabalho implica na transformação econômica da sociedade". ${ }^{13}$ O projeto de constituição (de 19 de junho), depois de haver proclamado o "direito ao trabalho" entre os direitos garantidos em seu art. $2^{\circ}$, definira-o em seu art. $7^{\circ}$ como "aquele que tem todo homem de viver de seu trabalho". Este direito estaria acompanhado de uma política: "A sociedade deve, pelos meios produtivos e gerais de que dispõe, e que serão organizados posteriormente, prover um trabalho a todos os homens válidos que não possam procurar sê-lo de outro modo". O dispositivo completa-se com uma série de garantias, enumeradas no art. 132.

Mas o projeto original será modificado na Comissão. E, entre as mudanças, figura a supressão do direito ao trabalho, substituído por um direito à assistência, Entretanto, durante a discussão deste projeto na Assembléia, a oposição entre "direito ao trabalho" e "direito de propriedade" — ou, para se formular de forma positiva, a relação entre direitos sociais e transformação social — aparece em toda a sua dimensão. Os socialistas não são os únicos que estabelecem uma correlação entre "direito ao trabalho" e (negação do) direito de propriedade. "Se o escrevermos na Constituição — disse Duvergier de Hauranne tomamos nesse mesmo instante a obrigação de mudar radicalmente todas as condições sociais" (p. 130). O impacto político de seu reconhecimento jurídico-constitucional aparece também muito claramente expresso nas reflexões de Tocqueville, que busca quebrar toda continuidade entre a Revolução de 1789 e "a social”, para poder distinguir logo entre a

\footnotetext{
${ }^{11}$ GARNIER, J. (Ed.). Le Droit au Travail à l'Assemblée Nationale. Recueil complet de tous les discours prononcés dans cette mémorable discussion (1848). reimpr. Paris, 1984. p. 408.

12 Id. Ibid., p. VII.

13 VIDAL, François. Vivre en travaillant! Projets, voies et moyens de réformes sociales. Montargis: 1997. p. 28.
} 
caridade e um direito dos trabalhadores sobre o Estado. E, ainda mais nitidamente, na posição falsamente paradoxal de Thiers, que é contrário ao reconhecimento do "direito ao trabalho", mas promove uma política ativa do Estado em matéria econômica e social. Para Thiers, um direito não deve confundir-se com uma política social: um direito se aplica a todos, sem exceção, enquanto que um "direito ao trabalho" (como se dirá mais tarde dos direitos sociais) se dirige a uma categoria específica. Para insistir sobre o caráter de direitos do homem, um socialista como Ledru-Rollin está disposto a aceitar uma mera declaração formal, admitindo que sua realização fosse imaginada em um futuro mais ou menos distante. ${ }^{14}$ Com efeito, mesmo aqueles que são favoráveis ao reconhecimento explícito do "direito ao trabalho", como Mathieu (de la Drôme), que reintroduz a questão no debate parlamentar, retiram explicitamente também sua garantia. Mais tarde, inclusive Proudhon dirá que embora o "direito ao trabalho" expresse uma necessidade respeitável, é, no fundo, irrealizável — estabelecendo a distinção entre "reconhecimento do direito" e a sua "realização". ${ }^{15}$

Não é casual o fato de que quem nega então todo valor jurídico ao "direito ao trabalho", o subsuma no "direito à assistência". ${ }^{16}$ Finalmente, o art. VIII do Preâmbulo associa a assistência à possibilidade dos cidadãos desvalidos de procurar "um trabalho dentro dos limites de seus recursos". O art. 13, do texto definitivo da Constituição estabelece, em um mesmo plano, que a "sociedade favorece e estimula o desenvolvimento do trabalho pelo ensino primário gratuito, a educação profissional, a igualdade nas relações patrãoempregado, as instituições de fomento e crédito e a liberdade de associação", ao mesmo tempo em que "promove a assistência aos menores abandonados, aos desamparados e aos idosos sem recursos, cujas famílias não podem ajudá-los”. Entretanto, o primeiro projeto de preâmbulo, em seus arts. $7^{\circ}$ e $9^{\circ}$, respectivamente, havia estabelecido claramente a diferença: enquanto que "o direito ao trabalho" é próprio a "cada homem", o direito à assistência pertence "aos menores abandonados, aos desamparados, aos idosos". Finalmente, a Constituição, de 1848, torna precisa a lógica que já havíamos visto na Constituição, de 1793, limitando a concessão de trabalho aos recursos existentes do Estado, por meio de obras públicas. Em ambos os casos, os titulares do direito não são os homens,

\footnotetext{
${ }_{14}$ TOCQUEVILlE, A. Oeuvres complètes. Écrits et discours politiques. Tomo III. Paris: 1990. O discurso de Thiers está em Le droit au travail à l'Assemblée nationale, cit. Sobre esse ponto, veja-se também ROSANVALLON, Pierra. op. cit., p. 158.

${ }_{15}$ PROUDHON, Pierre Joseph. Idée generale de la Révolution au XIXe siécle. Paris: 1979. p. 167-168.

${ }^{16}$ Encontramos afirmações equivalentes em outros socialistas, distintos de Blanc e Proudhon, no que poderia ser, diante de tudo, uma estratégia para fazê-lo emergir em um texto constitucional que, finalmente, não o reconhece.
} 
mas os necessitados. A partir de então, os direitos sociais encontram-se ligados não-só à particularidade de uma categoria social, mas sempre à atividade benfeitora do Estado.

Em todo caso, isto é o que reterá uma testemunha do processo francês, cuja influência sobre as idéias sociais será determinante nas concepções da outra margem do Reno, do Kaiserreich à República Federal: Lorenz von Stein. Segundo Stein, o movimento social põe a reforma no terreno das classes possuidoras, podendo, assim, evitar a revolução social. Disso resulta uma aritmética política, na qual o Estado, enquanto administração social-reformista, deve garantir à classe expropriada a aquisição de capital, superando assim o primeiro conteúdo social da idéia de igualdade, a negação da propriedade privada. Neste sentido, o social coloca-se explicitamente fora da constituição, para ser concentrado na administração. ${ }^{17}$

A questão social, e seus espectros, percorre a Europa. E, no plano do pensamento, serão as correntes do liberalismo social, caracterizado, na França e na Alemanha, por um forte componente cristão, quem irá estabilizar, e logo absolutizar, o elemento de integração social. Além das tentativas bonapartistas, encontraremos no Estado bismarckiano uma primeira realização sistemática, a partir das leis de seguro de enfermidades, em 1883, e de seguro de acidentes, no ano seguinte, inaugurando, assim, uma tradição autoritária do Estado de Bem-Estar. Mas esse dispositivo de política social não inclui um reconhecimento constitucional de direitos sociais — esta, de fato, como é conhecido, estava inclusive acompanhada por uma legislação repressiva anti-socialista, que começa com a lei de 1878 e prolonga-se até o "novo curso" de 1890.

No entanto, é neste período que começamos a encontrar a noção de "direitos sociais" como "direitos fundamentais". Uma das primeiras formulações, a primeira de nosso conhecimento, aparece na doutrina de Anton Menger, que emprega a expressão "direitos econômicos fundamentais" (ökonomische Grundrechte) do socialismo. Para Menger, estes eram três: o "direito ao produto integral do trabalho", o "direito à existência" e o "direito ao trabalho". Entretanto, como se pode apreciar de sua mera enunciação, esse "fundamental", reenvia mais a uma visão filosófica que jurídico-positiva, embora Menger imagine um Estado social que realizará estes "direitos". Mas Menger é um teórico pós1848, discípulo de Stein, que pensa esse Estado "popular de trabalho" como "um sistema jurídico que reconhece a cada membro da sociedade o direito de obter, em proporção aos

\footnotetext{
17 STEIN, Lorenz von. Geschichte der sozialen Bewegung in Frankreich, von 1789 bis auf unsere Tage. München: 1921, Tomo III, p. 193 e ss. Stein considera que a forma da constituição é indiferente às classes despossuídas, porque ainda que seus interesses (sociais) fossem levados em conta, isto não se faria senão de maneira lenta.
} 
recursos existentes, os bens e serviços necessários para uma existência humana, antes que as necessidades menos urgentes de outros cidadãos sejam satisfeitas", ${ }^{18}$ numa lógica que recorda as formulações de um John Rawls.

\section{Direitos Sociais e Constitucionalismo Social}

A questão da constitucionalização do social ressurge de maneira vigorosa com as revoluções do período do entre-guerras. Este processo, que se estende ao menos até a Constituição da Segunda República espanhola de 1931, dará lugar à denominação característica de "constitucionalismo social”, para referir-se ao movimento de incorporação de cláusulas programáticas de conteúdo econômico e social nos textos constitucionais.

A história constitucional tem oficialmente a sua certidão de nascimento com a Constituição alemã, de 11 de agosto de 1919. Mas, para dizer a verdade, esta já tem um precedente fundamental na Constituição mexicana, de 5 de fevereiro de 1917 , elaborada em Querétaro. Se este antecedente não pode ser evitado, não se trata de um simples (e inútil) gesto de erudição: encontramos ali, estabelecida pela primeira vez em um texto constitucional que alcançará vigência, a relação específica entre direitos sociais e revolução inconclusa.

Nos debates constitucionais, iniciados em dezembro de 1916, os constituintes mexicanos assumem que sua proposição supera os moldes tradicionais da Ciência do Direito, pela inclusão na constituição de normas consideradas tradicionalmente como regulamentares, em matéria de direito do trabalho e organização econômica. Nesse sentido, estavam perfeitamente conscientes da importância de sua obra, como assinalou nos debates da Assembléia Constituinte um de seus membros, nem sequer representante da ala radicalizada: “assim como a França, depois de sua revolução, teve a alta honra de consagrar na primeira de suas cartas magnas os imortais direitos do homem, assim a Revolução Mexicana terá o orgulho legítimo de mostrar ao mundo que é a primeira em consignar em uma Constituição os sagrados direitos dos trabalhadores". ${ }^{19}$

Com efeito, a Revolução, iniciada em 1910 em nome dos princípios políticos do liberalismo, adquire rapidamente um conteúdo social. ${ }^{20}$ A questão encontra-

\footnotetext{
${ }_{18}$ MENGER, A. El derecho al producto íntegro del trabajo en su desarrollo histórico. Buenos Aires: 1944. p. 19 e ss., Neue Staatslehre (1903), trad. francesa, p.138.

19 CRAVIOTO, A. op. cit. em ROUAIX, P. Génesis de los artículos 27 y 123 de la Constitucion politica de 1917. México: 1978. p. 72. Rouaix foi o presidente das comissões encarregadas de redigir estes artigos.

${ }^{20}$ Como mostra a leitura dos diferentes "Planes" desde 1911, mas sobretudo a partir de 1913. Assim, o reconhecimento constitucional, de 1917, foi precedido de uma importante legislação nos diferentes Estados, por via de leis e decretos durante as operações militares, que instauraram a jornada de trabalho, o salário
} 
se delineada por quem se transforma em seu principal chefe, Venustiano Carranza, em um discurso de setembro de 1913: “A luta social, a luta de classes, queiramos ou-não queiramos nós mesmos, e oponham-se as forças que se opuserem, as novas idéias sociais terão que impor-se às nossas massas: e não é só repartir as terras e as riquezas nacionais, não é só o sufrágio efetivo, não é só abrir mais escolas, não é só igualar e repartir as riquezas nacionais; é algo maior e mais sagrado: é estabelecer a justiça, é buscar a igualdade, é a desaparição dos poderosos, para estabelecer o equilibrio da consciência nacional". ${ }^{21}$ Esta idéia de integração social é central, e a encontramos também em outros atores, como o General Alvaro Obregón — vencedor de Villa e referência da esquerda na Assembléia de Querétaro - para quem a legislação social e inclusive o socialismo "tem como alvo principal estender a mão aos de baixo para buscar um maior equilíbrio entre capital e trabalho".22

Para além dos efeitos retóricos, e, sobretudo, de um assumido projeto político de harmonização social, a idéia de justiça está ligada à de transformação. Carranza, chefe provisório do executivo, aparece como promotor de uma importante legislação social, além de iniciador da revisão constitucional de 1916-1917. Entretanto, no projeto de constituição que envia à Assembléia, a questão social não foi incluída, por considerar que se tratava de matéria regulamentar. São os constituintes radicais - que se fazem chamar de "jacobinos" — que pressionam para incluí-la, obtendo após várias negociações, o apoio dos homens de Carranza, conseguindo com que os artigos sejam, finalmente, aprovados por unanimidade.

Mas a importância da Constituição mexicana, de 1917, supera o marco ideológico que a sustenta, porque constitui o dispositivo jurídico próprio do constitucionalismo social da primeira metade do século XX. Neste caso, este se concentra em três artigos: o $5^{\circ}$, cujo debate dará origem à questão social na Constituição, o 27 e o 123 (com seus trinta incisos originais). Esta tríade começa com a afirmação, no primeiro de seus artigos, de uma garantia especial de igualdade, e se completa logo com um mecanismo dialético que afirma, por um lado, os direitos dos trabalhadores, e, por outro, a limitação

mínimo, o descanso semanal obrigatório, a proteção dos mineiros, etc. Ver Fuentes para la Historia de la Revolución Mexicana. I. Planes políticos y otros documentos (1954), México, 1974.

${ }^{21}$ Cit. por SAYEG HELÚ, J. La revolución mexicana a través de sus documentos fundamentales. México, 1996, p. 203. Carranza havia enviado seu principal jurista de confiança, José Natividad Macías, estudar a legislação e as relações trabalhistas nos Estados Unidos, assim como a legislação inglesa e belga, que eram consideradas das mais avançadas da época.

${ }^{22}$ Citado por CÓRDOBA, A. México. Revolución burguesa y política de masas. In: GILLY, Adolfo (Org.). Interpretaciones de la Revolución Mexicana. México: Nueva Imagem/UNAM, 1979, 1994, p. 79. O Autor fala de "uso contra-insurrecional das reformas sociais" (p. 72). 
da propriedade privada. Assim, não há direitos sociais, como projeto de realização de uma ordem social diferente, sem uma limitação correlata do direito de propriedade. $\mathrm{O}$ art. $5^{\circ}$, incluído na parte dogmática das garantias individuais - e que fôra apresentado pelos constituintes como um "direito à vida completa" —, prevê a proteção do Estado nas relações de trabalho e o princípio de contrato de trabalho. $\mathrm{O}$ art. 27, considerado como o mais importante da Constituição dada a estrutura agrária do México, enuncia o principio da limitação da propriedade privada pelo interesse público, consagrando sobretudo os princípios de expropriação e da reforma agrária. $\mathrm{O}$ art. 123 condensa os direitos relativos ao trabalho e à sua proteção, consagrando com caráter constitucional o salário mínimo (VI e seguintes), a jornada legal de trabalho de oito horas (incisos I a III), o direito de associação (XVI), o direito de greve (XVII), a participação dos trabalhadores nos lucros da empresa (VI e IX), a responsabilidade patronal nos acidentes de trabalho (XIV), o estabelecimento de Juntas de conciliação e arbitragem tripartite (trabalhadores, empresas, governo) para regular os conflitos entre o capital e o trabalho (XX) e a indenização em caso de dispensa (XXII).

Embora rechacem incluir o art. 123 na parte dogmática da Constituição, como exigem, em um primeiro momento, os deputados radicais, porque este não compreenderia toda a nação, os constituintes de esquerda apresentam esses artigos como a via para "tirar o trabalhador do meio onde vive para colocá-lo, como homem, na sociedade". ${ }^{23}$ Esta tensão entre integração e emancipação inscreve-se no próprio coração do dispositivo constitucional. Embora se reconheça, pela primeira vez com estatura constitucional, o direito de greve, o contrato de trabalho, a participação dos trabalhadores nos lucros das empresas, interpretados como princípios dinâmicos para a transformação social, estes estão ao mesmo tempo enquadrados — assim, a greve é lícita se ela "harmoniza os direitos do trabalho com o capital". ${ }^{24}$

O contexto da constitucionalização social na Europa estará marcado também pela radicalização dos setores sociais dominados em um estado de exceção dado pela Grande Guerra, primeiro, e pela Revolução, depois. Nesse marco, a radicalização crê encontrar, ainda, uma forma institucional nova e concreta, os Conselhos, atualizados pela Revolução Bolchevique, de outubro de 1917. Nesse sentido, a "Declaração dos Direitos

\footnotetext{
${ }^{23}$ Discursos de H. JARA (radical), cit. em FERRER MENDIOLEA, Gabriel. Historia del Congreso Constituyente de 1916-1917. México: Binehrm, 1957. p. 140.

${ }^{24} \mathrm{O}$ sentido dado pela comissão era o de fixar "os direitos que lhes correspondam (aos trabalhadores) nas relações contratuais com o capital, a fim de harmonizar, enquanto é possível, os contrapostos interesses deste e do trabalho, pela arbitrária distribuição dos lucros obtidos na produção". Fala-se, assim, de reformas sociais com "prudência e acerto". (ROUAIX, P. op. cit., p. 92).
} 
do Povo Trabalhador e Explorado", de janeiro de 1918, mais tarde incorporada à primeira constituição soviética (julho), contém em seus quatro capítulos não tanto um catálogo de direitos, mas a explicitação de princípios de organização política e econômica: direitos sociais e organização social fundem-se ao extremo. A Declaração atribui aos sovietes "como tarefa essencial, a abolição de toda exploração do homem pelo homem, a eliminação total da divisão da sociedade em classes, o esmagamento implacável da resistência dos exploradores, a organização socialista da sociedade e a vitória do socialismo em todos os países", ligando esta proclamação a uma série de medidas concretas, como a abolição da propriedade privada da terra, a nacionalização das riquezas naturais, das fábricas e dos bancos, o controle operário sobre todos os meios de produção, o trabalho obrigatório, o armamento dos trabalhadores, a exclusão da burguesia dos órgãos de poder. Um programa que gerou, como sabemos, uma grande atração para as massas européias.

Frente a este "modelo soviético" (a superar), reaparece na reflexão do Direito Público a idéia de um "Estado social", que será desenvolvida na Assembléia de Weimar por Friedrich Naumann, seu defensor mais lúcido naquele momento. ${ }^{25}$ Em Naumann, o Estado social conserva as raízes desta política de integração que remontava, na Alemanha, à política das elites prussianas do século XIX, mas, sobretudo, prolonga-se, ante o novo contexto, com um reconhecimento dos "direitos dos homens associados" (der Verbandmensch). O Estado social aparece como uma espécie de nova síntese orgânica do objetivo de integração, eqüidistante do individualismo ocidental e do coletivismo russo.

Embora as diferentes propostas de fazer uma declaração de direitos, como a que propõe Naumann, fossem rechaçadas pela Assembléia de Weimar, a Constituição, de 1919, retoma os postulados do constitucionalismo social, no marco do compromisso entre três grandes programas políticos, o liberal social, o católico social e o socialista. Encontramos, assim, a constitucionalização de direitos de certos grupos sociais (família, juventude, menores, mães, funcionários) e o reconhecimento de direitos à educação e moradia. Sobretudo, o texto constitucional resguarda em seus dispositivos um conjunto de direitos "econômicos" e os direitos dos trabalhadores, especialmente no art. 165, integrados no seio do que a doutrina jurídica alemã da época chamará de "constituição econômica" (Capítulo V, arts. 151-165).

A preocupação em teorizar esta constitucionalização do social encontra-se, sobretudo, em juristas marginais, especialmente, socialistas. Um deles, Hugo Sinzheimer, redator do célebre art. 165, que previa a organização de conselhos econômicos de

${ }_{25}$ RITTER, Gerhard. op. cit., p. 102-103. 
trabalhadores e empresários para regular a atividade econômica e as relações trabalhistas, havia defendido nos debates constituintes a velha idéia de uma "constituição social", específica, ao lado da constituição política. No fundo, entretanto, os intentos de dar conta do novo constitucionalismo ficaram encerrados nos termos do debate alemão da época. Por um lado, a doutrina positivista dominante, que via nos direitos fundamentais, incluídos os de conteúdo individual, antes de tudo, um programa, cuja maior parte não era realizável pelo juiz sem uma lei, que podia, inclusive, limitá-los. Por outro, os juristas que se mostram mais dispostos a reconhecer uma força jurídica total a tais direitos, como Carl Schmitt, consideram, ao mesmo tempo, que os direitos "sociais" contidos na segunda parte da Constituição, de 1919, são "socialistas por essência", no plano dos fundamentos, porque se apresentam como um direito de todos que supõe uma nova organização estatal, e limitados, no plano técnico, porque se trata de prestações do Estado, que pressupõe uma organização especifica nesse sentido. Sobretudo por sua "estrutura lógica e jurídica", estariam em contradição com os "verdadeiros direitos fundamentais", quer dizer, aqueles negativos de liberdade individual, próprios a um Estado de direito burguês como o consagrado pela Constituição. ${ }^{26}$

Frente a tais posturas, os juristas social democratas concebem os direitos fundamentais como direitos "culturais" que teriam por origem, não o indivíduo abstrato, mas o desenvolvimento da cultura política de uma comunidade. ${ }^{27}$ Esta visão pode integrar os componentes da tradição social do liberalismo alemão, de onde provinham alguns dos mais experimentados juristas socialistas. Sinzheimer verá inclusive em Lorenz von Stein um precursor de suas idéias sociais, e a noção de "Estado de cultura e bem-estar" (Kultur-und Wohlfahrtsstaat) podia passar de Adolf Wagner a Gustav Radbruch, enquanto que Hermann Heller não duvidava em saudar a "grande" obra social de Bismarck. ${ }^{28}$ Esta tradição jurídica socialista sobre os direitos sociais constrói-se em torno de três eixos de análise, em que pese o seu entrecruzamento. O mais sistemático destes intentos buscará analisar o conjunto das transformações jurídicas através da idéia de direito social, que

\footnotetext{
${ }^{26}$ SCHMITT, C. Verfassungslehre (1928), Berlim, 1993, pp. 169-170 e 181-182 (trad. espanhola, pp. 174 e 184). O livro de Schmitt, assim como as análises contemporâneas de Smend sobre a força integradora dos direitos fundamentais, tiveram um eco muito importante na doutrina da época, incluindo a positivista. Vide, por exemplo, R. THOMA, "Die juristische Bedeutung der grundrechtlichen Sätze der Deutschen Reichsverfassung im allgemein", in H. C. NIPPERDEY (ed.), Die Grundrechte und Grundpflichten der Reichsverfassung, Berlim, 1929, Tomo I.

${ }^{27}$ HELLER, H. Grundrechte und Grundpflichten. (1924). In: Gesammelte Schriften. Leiden: 1971, Tomo II, p. 286.

${ }^{28}$ Cf. nosso trabalho "La social-démocratie et le concept d'Etat de droit à Weimar" (2000), incluído agora em tradução espanhola em HERRERA, C. M. Derecho y socialismo en el pensamiento jurídico. Bogotá, 2002. V. também, RITTER, G. op. cit., p. 76 e 118.
} 
emerge como categoria jurídica geral. Nela há lugar para uma nova antropologia do homem concreto, individualizado, como dirá Radbruch. Em um eixo mais estrito do Direito Constitucional, Heller concebe os direitos sociais, como o "direito ao trabalho" reconhecido no art. 163, como "princípios programáticos", e não como Direito Positivo, válido. Para este constitucionalista socialista, o espírito da Constituição, de 1919, é de harmonização, para uma distribuição de bens mais justa (p. 312), em oposição à luta de classes, uma diferença que encontramos na distinção que faz entre as idéias "sociais", realizadas pela intervenção do Estado através de uma política social e econômica, e as "socialistas", que buscam a socialização da propriedade e da produção. Nesta última perspectiva se inscrevem, constituindo um terceiro eixo, os trabalhos de Franz Neumann, que busca construir uma espécie de teoria socialista dos direitos fundamentais. Este jovem advogado trabalhista sustenta, assim, que o art. 151, com seu proclamado objetivo de garantir uma existência humana digna ("eine menschenwürdigen Dasein"), consagrava uma concepção material da justiça que enquadra (e condiciona) os chamados direitos capitalistas de propriedade, contrato e livre empresa. A "constituição econômica" continha um programa de ação: a realização legal da liberdade social, ou, dito de outra forma, a possibilidade dos trabalhadores de determinarem suas formas de existência. ${ }^{29}$ Em que pese considerar o Estado social como "constitucional", Neumann, como de fato outros juristas socialistas, insiste menos no conteúdo social dos direitos proclamados na segunda parte da Constituição, de 1919, que na importância dos mecanismos institucionais previstos para a socialização da propriedade (art. 156) e a administração da economia através de Conselhos de empresa (art. 165). A crítica do jovem Marx aos direitos do homem, de 1789, e seu caráter abstrato e apolítico se interpunha, talvez, em toda compreensão socialista do jurídico.

\section{Direitos Sociais e Estado de Bem-Estar}

Os desenvolvimentos constitucionais na segunda metade do século XX debilitarão a relação entre constitucionalização de direitos sociais e mudança social. Com efeito, esta segunda onda de constitucionalismo social, que surge em países liberados de ditaduras totalitárias, vai constitucionalizar os direitos sociais em uma direção particular,

\footnotetext{
${ }^{29}$ NEUMANN, F. Die soziale Bedeutung der Grundrechte in der Weimarer Verfassung. Die Arbeit, 1930. p. 582. Para uma periodização do debate constitucional na social democracia weimariana, ver nosso trabalho Constitution et social-democratie à Weimar, HERRERA, C. M. (ed.). Les juristes de gauche sous la République de Weimar. Paris, 2002.
} 
a da integração social..$^{30}$ É também o momento em que se opera uma coincidência entre o reconhecimento dos direitos sociais e o desenvolvimento de um Estado intervencionista de novo tipo, o Estado de Bem-Estar. Nesta constelação concreta e complexa fixam-se os fundamentos jurídicos dados aos direitos sociais até nossos dias.

A especificidade desta nova configuração do Estado social que constitui o Estado de Bem-Estar reside em sua pretensão de eliminar a idéia de particularidade da necessidade, ligada a uma categoria social determinada, que era parte essencial da primeira matriz do Estado intervencionista. Através da extensão do sistema de seguridade social a todos os cidadãos, sem limites de renda, a idéia de integração social toma a forma da universalidade. A expressão clássica desta concepção encontra-se nos célebres relatórios Beveridge, de 1942 e 1944. Como sabemos, esse modelo busca eliminar as necessidades através da instituição de seguros sociais obrigatórios. Com efeito, para Beveridge, a ausência de capacidade de renda (pelo desemprego, mas também pela enfermidade, invalidez, velhice), é a causa das necessidades de subsistência. Mas esta universalização da necessidade inscreve-se sempre em uma lógica de integração social, expressada antes de tudo nas políticas de pleno emprego que, como sublinha o próprio Beveridge, pode ser obtido com a indústria em mãos privadas. ${ }^{31}$

A nova constitucionalização social que surge depois da Segunda Guerra Mundial, insere-se nesse novo modelo de Estado intervencionista, mesmo quando as novas constituições, como a italiana, de 1947, realizam uma ampla recepção normativa dos direitos sociais, que inclui inclusive um "direito ao trabalho" (art. 4"). Se a Lei Fundamental de Bonn não codificou, apegada a uma velha tradição alemã, os direitos fundamentais de caráter social (com exceção da proteção da família, art. $6^{\circ}$, e o estatuto dos funcionários públicos, art. 33), ${ }^{32}$ proclama no art. 20 e também no 28 , o chamado

\footnotetext{
${ }^{30}$ Ainda que a existência de uma relação, mesmo que débil, entre a constitucionalização dos direitos sociais e um momento insurrecional possa ser rastreada em certos momentos do texto constitucional positivo ou de sua interpretação jurisdicional (compare-se a Itália com a Alemanha, ou Portugal com a Espanha).

${ }^{31}$ BEVERIDGE, W. Full employement in a free society (1944). Londres, 1945. p. 23 e 37. Na realidade, a questão da universalidade do sistema social de proteção não parece ser a contribuição mais original de Beveridge, na medida em que esta se encontra já em certa tradição socialista inglesa. Em particular, a idéia era defendida no informe sobre as English Poor Law Policies, realizado pelos socialistas Beatrice e Sidney Webb, de quem Beveridge fôra secretário. Os Webb sustentavam que o princípio de universalidade, "sem consideração da indigência ou da incapacidade de procurar recursos diretamente", deveria ser o elemento novo do sistema de assistência pública em relação aos modelos precedentes do século XIX, e que eram "incompatíveis com a própria natureza da administração da indigência". A negação total da administração da indigência implica para eles no princípio de prevenção das causas de aparição desse estado (p. 75).Ver WEBB, S. y B. Le problème de l'Assistance publique en Angleterre (1910). Paris, 1912. p. 17 e 47.

32 DAÜBLER, W. “Allemagne” em ILIOPOULOS-STRANGAS, J. (Ed.). La protection des droits sociaux fondamentaux dans les États membres de l'Union européenne. Atenas, Bruxelas, Baden-Baden, 2000. p. 60.
} 
princípio do "Estado social", que condiciona a interpretação de seu catálogo de direitos individuais, sobretudo a partir do princípio da igualdade.

Na França, os debates constituintes, de 1945-1946, pretendem dar conta, por sua vez, do constitucionalismo social e do Estado intervencionista. O projeto de constituição, de 19 de abril de 1946, havia reconhecido amplamente, na segunda parte de sua declaração dos direitos do homem, os "direitos sociais e econômicos" (arts. 22 a 39). Este catálogo abria-se com a afirmação de que "todo ser humano possui, em relação à sociedade, os direitos que garantem, na integridade e na dignidade da pessoa, seu pleno desenvolvimento físico, intelectual e moral". Mas não se tratavam de direitos fundamentais em sentido estrito, a partir do momento em que o segundo inciso do art. 22 assinala que "a lei organiza o exercício destes direitos". Após o rechaço referendário deste projeto, o preâmbulo da Constituição definitivamente adotada em outubro não se voltará aos direitos sociais mais que sob a forma de "princípios particularmente necessários a nosso tempo", que entendiam completar os velhos direitos de 1789. Se as vicissitudes e o fim da IV República, por um lado, e a jurisprudência refratária diante do preâmbulo de parte da principal jurisdição da época, o Conselho de Estado, por outro, fizeram crer na debilidade do constitucionalismo social na França, sua incorporação no "bloco de constitucionalidade" definido pelo Conselho Constitucional, já sob a V República, a partir de um conjunto de decisões no final dos anos 1970, fizeram ressurgir o problema do conteúdo dos enunciados, do preâmbulo de 1946, diante da questão jurídica dos direitos sociais. $^{33}$

Este texto condiciona duplamente a discussão sobre o sentido jurídico dos direitos sociais: por um lado, define-os como princípios políticos, econômicos e sociais, e não como direitos, parecendo impor, assim, uma concepção particular. ${ }^{34}$ Por outro, lhes dá um marco histórico-temporal preciso, ao definí-los como "particularmente necessários para nosso tempo", sujeitos necessariamente às evoluções de significado contrário, o que parece destacar ainda mais sua fragilidade jurídica. Entretanto, a própria redação do Preâmbulo parece mostrar de que se tratam, na realidade, de direitos: enunciam-se assim um "direito a obter emprego", um “direito de greve”, uma "garantia de proteção da saúde”,

\footnotetext{
33 Até meados dos anos 80 , uma parte importante da doutrina sustentava que o preâmbulo não constituía mais do que um conjunto de disposições desprovidas de efeitos jurídicos diretos. O desenvolvimento da jurisprudência do Conselho Constitucional em matéria social-constitucional é relativamente recente: podemos localizá-la, efetivamente, em fins dos anos 70, sobretudo a partir do reconhecimento do Estatuto Constitucional do Direito dos Trabalhadores à determinação coletiva das condições de trabalho, à gestão de empresas e o direito de greve.

${ }^{34}$ Assim, segundo Jean Rivero, esses direitos não apresentam "um valor universal e permanente". Cf. Les libertés publiques (1974), Tomo 1. Les droits de l’homme, Paris, 1995. p. 85.
} 
etc. Bem mais, pois, como fôra sublinhado oportunamente, a constituinte havia inovado em certos aspectos dos direitos sociais, em particular a respeito do velho "direito ao trabalho", que se encontra separado da noção do não menos antigo direito de assistência, em que pese que a interpretação do inciso 11 ("direito a obter da coletividade os meios convenientes de existência"), tende a integrar o "direito ao trabalho" dentro do "direito de assistência" para aqueles que não se encontram em condição de trabalhar. ${ }^{35}$

As novas constituições européias dos anos 70 compartilharão com suas antecessoras desta segunda metade do século XX o fato de surgirem após (longas) experiências ditatoriais. Mas, sobretudo, prolongavam de alguma maneira as experiências italiana e alemã no plano do constitucionalismo social. A codificação mais ambiciosa de direitos sociais encontra-se na Constituição de Portugal, de 1976, surgida da chamada "Revolução dos Cravos", e talvez fosse tentador inscrever os diferentes níveis de juridicidade alcançados pelos direitos sociais entre esta constituição e sua contemporânea espanhola, de 1978 - que, como vimos no início, prefere falar já só de "princípios dirigentes" (principios rectores)—, na distância que separa uma passagem à democracia constitucional por via insurrecional, em um caso, ou transicional, em outro. Mas as revisões constitucionais portuguesas, de 1982 e 1989, "normalizaram" rapidamente algumas de suas potencialidades normativas, inscrevendo-as no marco do Estado de Bem-Estar. A Corte constitucional portuguesa retomará, inclusive, o chamado princípio da "reserva do possível", elaborado pela Corte alemã em princípios dos anos 70 em sua decisão numerus clausus I, para os direitos sociais que impliquem uma prestação do Estado.

Um conceito jurídico selará esta coincidência entre o Estado de BemEstar e os direitos sociais, o de "Estado Social de Direito", cujas raízes remontavam ao debate weimariano. Não-obstante seu lugar um tanto marginal na Grundgesetz, de 1949 (art. 28), conheceu um certo sucesso, primeiro no plano doutrinal, para passar logo ao Direito Constitucional Positivo: foi incluído na Constituição espanhola, de 1978 (art. $1^{\circ}$, inc. 1; "Espanha é um Estado Social e Democrático de Direito") e, dali passou, nos anos 1990, às novas constituições de alguns países da América Latina (Colômbia, em 1991, art. $1^{\circ}$, Paraguai, em 1992, art. $1^{\circ}$ ). Em uma decisão da Corte Constitucional alemã do início dos anos 80 , podemos ler toda a ambigüidade que encerra a noção: “O princípio do Estado Social institui a obrigação do Estado de estabelecer uma ordem social justa, o legislador dispõe de uma ampla margem de atuação para o cumprimento desta obrigação. O princípio do Estado Social confia uma missão ao Estado, mas não diz nada sobre a

\footnotetext{
${ }_{35}$ Vide a discussão deste tópico em COLLIARD, C. A. Libertés publiques. 6. ed. Paris, 1982. p. 782-783.
} 
forma de realizá-la em detalhe — de outro modo, este princípio entraria em contradição com a democracia". ${ }^{36}$ A partir do momento em que a realização de um direito social implica em gasto econômico, a decisão não pode ultrapassar a esfera do legislador ou da administração, sob o risco de politizar a justiça. ${ }^{37}$ A doutrina alemã forjou a noção de direitos-diretivas (Massgabegrundrechte), dirigidos, antes de tudo, ao legislador.

A doutrina francesa deu conta dos direitos sociais com a categoria de direitos-crédito (droits-créances), em oposição aos direitos-liberdades, que segue sendo amplamente majoritária até os dias de hoje. ${ }^{38}$ Segundo Jean Rivero e Georges Vedel, num texto sobre o preâmbulo, de 1946, que constitui o framwork conceitual sobre a questão dos direitos sociais, "esses direitos supõem uma ação positiva por parte do Estado, seja com vista a prover prestações aos indivíduos (proteção da saúde ou da família, direito à cultura, etc.), ou com vista a organizar a vida econômica (associação de trabalhadores ou a gestão empresarial, progressividade dos impostos, direito de propriedade)" ${ }^{39}$ A noção de direitos-crédito, "pelos quais o indivíduo pode exigir do Estado prestações positivas"40 reenvia à idéia de um “Estado devedor” destas prestações. Mas se torna difícil conceber esta categoria, dada a ausência de sanção em caso de descumprimento da obrigação, ou, para dizer de outro modo, o caráter não jurídico de tal “obrigação". Se no desenvolvimento atual do Direito supraestatal (europeu e internacional), os mecanismos de sanção apresentam uma eficácia limitada para obrigar os Estados, pode-se inferir que não se trata de autênticos direitos. Na realidade, como admite Rivero (p. 49), estas obrigações não constituem a contrapartida de um direito reconhecido ao homem. Pelo contrário, "enquanto o serviço público não tiver sido criado, enquanto o Estado não tiver reunido os meios para liberar-se dessa dívida, o direito do credor não pode ser exercido". ${ }^{41}$

36 BVerfGE 59, 261 (Freie Mitarbeiter), 13/1/1982.

37 BÖCKENFÖRDE, E. W. Théorie et interprétation des droits fondamentaux. Tradução francesa em Le droit, l'État et la constitution démocratique. Paris, 2000. p. 272. Reconhecemos aqui um argumento de velha tradição schmittiana, que já havia sido atualizado por E. Forsthoff.

38 A expressão clássica em RIVERO, Les libertés publiques, cit. A doutrina francesa atual argumentou em favor desta categoria, porque ela insiste sobre o aspecto da obrigação de atribuição dos bens.

39 RIVERO, J.; VEDEL, G. Les principes économiques et sociaux de la Constitution : le Preambule, Droit social, 1947, p. 16. É a mesma posição de E. Forsthoff, para quem as garantias dos direitos sociais não observam a liberdade, mas a participação. Nesse sentido, os direitos liberais mantêm o status quo, "Der Rechtsstaat im Wandel", op. cit.

${ }^{40}$ RIVERO, J. Constitutions et structures sociales, p. 4, RIVERO, J.; VEDEL, G. Les principes économiques et sociaux de la Constitution... . op. cit., p. 34.

${ }^{41}$ RIVERO, J. Les libertés publiques. op. cit., p. 100. Um argumento próximo encontra-se em BÖCKENFÖRDE, Die sozialen Grundrechte im Verfassungsgefüge. In: Soziale Grundrechte. Heidelberg, 1981. p. 10-11. 
Este ponto é essencial, porque sob a teorização de um direito à prestação, vemos reaparecer um elemento discricionário, que fôra próprio da tradição caritativa do primeiro Estado Social, e que permitia justificar uma política social ativa, sem que ela implicasse no reconhecimento de direitos fundamentais a essas prestações (o exemplo tradicional de Bismarck). O caráter discricionário constitui justamente a diferença entre política social e direitos sociais. Como escreve Thiers durante os trabalhos da Comissão de Assistência e Previsão, de 1850, "importa que esta virtude, quando passa a ser de particulares, coletiva, de virtude privada a virtude pública, não perca esse caráter de virtude, quer dizer que se mantenha voluntária, espontânea, livre de fazer ou de não-fazer, porque, do contrário, deixaria de ser virtude para converter-se em coação".

Conclusão

Ao final deste percurso, parece possível reconhecer duas lógicas atuantes na construção da problemática dos direitos sociais fundamentais. Por um lado, aquela que tende a fazer desses direitos os vetores de uma mudança (radical) das relações sociais — o sentido polêmico que foi denunciado por Forsthoff. Por outro, uma visão encaminhada à integração das classes sociais em um Estado de Bem-Estar, e que se torna hegemônica, a partir de 1945.

A inscrição dos direitos sociais em uma modalidade específica de Estado Social, o Estado de Bem-Estar ${ }^{42}$ leva a um deslocamento de seus fundamentos, ou mais exatamente, à absolutização de uma de suas vertentes, com todas as conseqüências que dela derivam no plano jurídico. Sublinhamos que, neste modelo, os direitos sociais aparecem marcados duplamente pela marca do particularismo: um certo tipo de "direitos" (a prestações "sociais" concretas), próprio de uma certa categoria (os indigentes), para alcançar sua integração no conjunto social.

Esta visão condiciona inclusive a essa parte da doutrina que pretende defender a universalidade dos direitos sociais através da categoria de "solidariedade" ${ }^{43}$ Certamente,

\footnotetext{
${ }^{42}$ Uma pesquisa recente distingue três tipos de Estado de Bem-Estar: o liberal, o corporativista e o socialdemocrata. É neste último tipo em que os princípios de universalização e desmercantilização dos direitos sociais alcançam sua maior extensão, sendo por sua vez o tipo menos comum. Mas, como o próprio Autor assinala, este Estado opera sob o modelo de integração capitalista, comum aos três tipos, mudando somente a forma de estratificação social. Vide ESPING-ANDERSEN, G. Les trois mondes de l'État-providence (1990). Paris, 2000. p. 41 e ss. No entanto, o Autor utiliza a categoria de direitos sociais em um sentido geral, nãojurídico.

${ }^{43}$ Um exemplo é dado pelos trabalhos muito ricos de M. Borgetto. Mas a solidariedade não é mais que uma variante teórica de seu fundamento, em uma lógica de integração, e, portanto, uma redução, como faz uma parte da doutrina francesa atual, dos fundamentos dos direitos sociais à solidariedade. Dito fundamento está
} 
as doutrinas solidaristas, já na versão clássica de Léon Bourgeois, caracterizaram-se por opor a solidariedade, como direito, à caridade, como virtude. Esta doutrina pôde fundar a idéia de prestação numa dívida social, expressa em um quase-contrato. Entretanto, o solidarismo não é mais que uma concepção, por certo, avançada, de integração dos indigentes, na medida em que, como já denunciara Jaurès, não questiona a propriedade privada. $^{44}$

Sem dúvida, ao propor uma diminuição das desigualdades sociais, o modelo de Estado de Bem-Estar produz uma certa transformação social. ${ }^{45}$ Já o social-democrata Eduard Heimann, inspirador de Hermann Heller, havia sustentado, sob a Constituição de Weimar, que a política social era "a realização das idéias sociais no capitalismo contra o capitalismo", um corpo estranho ao sistema, em suma, que o conduziria a mudanças radicais (socialistas). ${ }^{46}$ Mas o Estado intervencionista tal como se desenvolve a partir de 1945, produz sempre transformações tendo em vista a integração social, separando, de fato, a política (social) dos direitos (sociais). É por isso que mesmo as concepções mais radicais desta vertente, aquela que pensa em termos de "cidadania social", aspiram a um modelo de Estado no qual a classe trabalhadora se integra, em termos de igualdade, na comunidade nacional.

Parece que os direitos sociais - começando pelo direito ao trabalho, o portador de maior radicalidade por razões históricas - não podem ser teoricamente concebidos sem a assunção de uma mudança correlativa no regime de propriedade. $\mathrm{O}$ que significa, em definitivo, assumir neles a lógica própria dos direitos do homem do século XVIII, que eram pensados em termos de emancipação humana. Isto explica porque só esta lógica permite pensar os direitos sociais em termos de universalidade, até seus últimos fundamentos.

Mas é a importância das conseqüências jurídicas que nos interessa sublinhar aqui, sobretudo se pensarmos que as limitações do modelo de direito à prestação para dar conta de uma parte importante dos direitos definidos como sociais, seja por suas origens ou repercussão, começando pelo direito de greve, que não exige do Estado, contrariamente

presente nas análises da doutrina constitucional francesa desde, pelo menos, as análises de Boris MirkineGuetzévitch, que já falava do controle social das liberdades individuais e da propriedade, e, anteriormente, embora de maneira menos clara, em Léon Duguit.

${ }^{44}$ Sobre este ponto, vide HERRERA, C. M. op. cit.

${ }^{45}$ Cf. BÖCKENFÖRDE, E. W. Naissance et développement de l'État de droit (1969). In: Le droit, l'État..., op. cit., p. 141. A teoria de Böckenförde é exatamente uma concepção sozialsstaatlich, ou seja, uma teoria dos direitos sociais que se apóiam sobre uma postura política determinada, aquela do Estado integrador.

${ }^{46}$ HEIMANN, E. Soziale Theorie des Kapitalismus. Theorie der Sozialpolitik. Tübingen, 1929. p. 118 e 225. 
ao que deixaria pensar o modelo, mais que uma ação puramente negativa. Para evitar estes inconvenientes, a doutrina tradicional se vê compelida a recorrer a adjetivos particulares ("social", "econômico") para nomear essas liberdades públicas. Entretanto a contingência do modelo de direito à prestação aparece também frente a outros direitos “sociais", como o "direito à saúde", que sofreram evoluções, por exemplo, na recente legislação francesa, que acentua a abstenção do Estado - até o ponto de nos encontrarmos perante "declarações de direitos dos pacientes", pensados na lógica de limitação de um poder absoluto (o do médico). Inclusive o próprio direito ao trabalho pôde ser concebido como um direito que limita o poder dos patrões (por exemplo, o debate constituinte francês, de 1946). Isto nos mostra o caráter complexo dos direitos chamados sociais, onde encontramos elementos que implicam em prestações e, ao mesmo tempo, em limitações. ${ }^{47}$

Para precisar o caráter jurídico dos direitos sociais como direitos do homem, talvez devamos operar um movimento de sentido inverso ao de seu desenvolvimento constitucional na segunda metade do século XX, desconectando-os justamente de um modelo histórico de Estado intervencionista, o Estado de Bem-Estar. Na origem dessa conexão, embora solidamente estabelecida, entre direitos sociais e Estado de Bem-Estar, podem ser encontradas mais de uma disfunção teórica, partindo da constatação de que o primeiro conceito deriva da tradição revolucionária do século XVIII, enquanto que a segunda noção faz referência à aplicação de uma política social sem fundamento jurídicoconstitucional, no final do século XIX. Sobre um plano algo mais técnico, esta desconexão nos permite também relativizar o argumento, próximo ao tautológico, que consiste em dizer que os direitos sociais não são aplicáveis por falta de um procedimento apropriado que corresponde, na realidade, a um certo modelo de poder judicial. Embora ainda os considerando como meros direitos programáticos em uma economia social de mercado, um tribunal, como fez a Corte Constitucional colombiana, em sua decisão de 23 de setembro de 1992, a respeito do direito à saúde, pôde considerar que um princípio "gera um direito público subjetivo de imediata aplicação", ${ }^{48}$

\footnotetext{
${ }^{47}$ Sobre este ponto, ver VAN HOOF, G. The Legal Nature of Economic, Social and Cultural Rights: a Rebuttal of Some Traditional Views. In: ALSTON, P.; TOMASEVSKI, C. (Eds.). The Right to Food. Dordrecht, 1984. p. 106-107 (e sua discussão recente em ABRAMOVITCH, V.; COURTIS, C. Los derechos sociales como derechos exigibles. Barcelona, 2002. cap. I).

${ }^{48}$ CORTE CONSTITUCIONAL, Sentença n. T-533. Em seus fundamentos jurídicos, a corte colombiana separa dois modos de intervenção perante a pobreza: as "causas estruturais, que são combatidas mediante políticas legislativas e macroeconômicas", e os "efeitos", que exigem "uma intervenção estatal direta e imediata", ainda que excepcional. No entanto, a doutrina da Corte Colombiana nesta decisão funda-se no princípio da dívida social do solidarismo, para interpretar o princípio da "solidariedade social", reconhecido pela Constituição, de 1991.
} 
A passagem pela política nos permitirá reencontrar a base teórica comum aos direitos individuais e aos direitos sociais, a universalização dos direitos do homem, como via para a emancipação da opressão social.

São Paulo, junho de 2007.

\section{Referências}

ABRAMOVITCH. V.; COURTIS, C. Los derechos sociales como derechos exigibles. Madrid, 2002.

AUTEXIER, Christian. Introduction au droit public allemand. Paris: PUF, 1997.

BEVERIDGE, W. Full employement in a free society (1944), Londres, 1945.

BLANC, L. Le Socialisme: le droit au travail. In: . Questions d'Aujourd'hui et de Demain. Paris: E. Dentun, 1882. tomo IV.

BÖCKENFÖRDE, E. W. Théorie et interprétation des droits fondamentaux. Tradução francesa em Le droit, l'État et la constitution démocratique. Paris, 2000.

. Die sozialen Grundrechte im Verfassungsgefüge. In: Soziale Grundrechte. Heidelberg, 1981.

BORGETTO, Michel. La notion de fraternité en droit public français. Paris, 1993.

CASTEL, Robert. Les métamorphoses de la question sociale. Paris, 1999.

COLliARD, C. A. Libertés publiques. 6. ed. Paris, 1982.

CÓRDOBA, A. Interpretaciones de la Revolución mexicana (1979). México DF, 1994.

DAÜBLER, W. Allemagne. In: ILIOPOULOS-STRANGAS, J. (Ed.). La protection des droits sociaux fondamentaux dans les États membres de l'Union européenne. Atenas, Bruxelas, BadenBaden, 2000.

FERRER MENDIOLEA, G. Historia del Congreso Constituyente de 1916-1917. México DF, 1957.

FORSTHOFF, Ernst. Rechtsstaat im Wandel. München: Beck, 1976.

GARNIER, Joseph. (Ed.). Le Droit au Travail à l'Assemblée Nationale. Recueil complet de tous les discours prononcés dans cette mémorable discussion (1848). reimpr. Paris, 1984. 
HEIMANN, E. Soziale Theorie des Kapitalismus. Theorie der Sozialpolitik. Tübingen, 1929.

HELLER, H. Gesammelte Schriften. Leiden, 1971.

HERRERA, C. M. Derecho y socialismo en el pensamiento jurídico. Bogotá, 2002.

HOOF, G. van. The Legal Nature of Economic, Social and Cultural Rights: a Rebuttal of Some Traditional Views. In: ALSTON, P.; TOMASEVSKI, C. (Eds.) The Right to Food. Dordrecht, 1984.

MENGER, A. El derecho al producto íntegro del trabajo en su desarrollo histórico (1886). Buenos Aires, 1944.

. Neue Staatslehre (1903). Tradução Francesa.

MÉXICO D.F. Fuentes para la Historia de la Revolución Mexicana. I. Planes políticos y otros documentos (1954). México D. F., 1974.

NEUMANN, F. Die soziale Bedeutung der Grundrechte in der Weimarer Verfassung. Die Arbeit, 1930.

PROUDHON, P. J. Oeuvres Complètes. Le Droit au Travail et le Droit de Propriété. nova edição. Paris, 1926. . Idée generale de la Révolution au XIXe siécle (1851). Paris, 1979.

RIVERO, J. Les libertés publiques (1974). T. 1, Les droits de l'homme, Paris, 1995.

.; VEDEL, G. «Les principes économiques et sociaux de la Constitution : le Prembule», Droit social, 1947.

ROBESPIERRE, «Discurso de 2 de dezembro de 1972», em Textes Choisis, T. II, Paris, 1957.

ROUAIX, P. Génesis de los artículos 27 y 123 de la Constitucion politica de 1917 (1945). México, 1978.

SAYEG HELÚ, J. La revolución mexicana a través de sus documentos fundamentales, México DF, 1996.

SCHMITT, C. Verfassungslehre (1928), Berlim, 1993.

STEIN, L. von. Geschichte der sozialen Bewegung in Frankreich, von 1789 bis auf unsere Tage (1850), (ed. Salomon), München, 1921.

TOCQUEVILLE, A. Ecrits et discours politiques, Oeuvres complètes, T. III, Paris, 1990. 
VIDAL, F. Vivre en travaillant! Projets, voies et moyens de réformes sociales (1948), Montargis, 1997.

WEBB, S. y B. Le problème de l'Assistance publique en Angleterre (1910), Paris, 1912. 